\title{
Rekontekstualisasi Estetika Hindu 'Rasa' Dalam Desain Arsitektural
}

\author{
I Kadek Dwi Noorwatha
}

\author{
Program Studi Desain Interior, FSRD \\ Institut Seni Indonesia Denpasar
}

noorwatha@gmail.com

Tulisan ini bertujuan untuk membahas proses rekontekstualisasi estetika Hindu 'rasa' dalam desain arsitektural kekinian. Metodenya adalah kajian perpustakaan (library research) dengan pendekatan hermeneutik dalam menginterpretasikan objek penelitian berupa teks estetika Hindu, maupun komparasinya dengan keilmuan desain arsitektural. Literatur utamanya mengacu ke Kitab Natyashastra oleh Bharata Muni dan proses rekonstekstualisasinya menggunakan analogi dramaturgikal (Attoe, 1979) dan manifestasi 'rasa' ke seni visual dan arsitektur (Shetty dan Bhoosan, 2017) dan (Verma dan Gupta, 2015). Hasil penelitian menunjukkan bahwa estetika Hindu khususnya teori 'rasa' relevan dikembangkan ke dalam keilmuan desain arsitektural kekinian. Relevansi tersebut bukan semata kesesuaian istilah semata, namun juga kesesuaian dengan materi pokok kelimuan desain arsitektural seperti bentuk, penciptaan spasial, konteks arsitektural sebagai tuntutan desain arsitektural kekinian.

Kata Kunci: estetika hindu, desain interior, rekontekstualisasi

\section{Hindu Aesthetics 'Rasa' Recontextualisation on Architectural Design}

This paper aims to discuss the process of recontextualization of Hindu aesthetics 'taste' in contemporary architectural design. The method is library research with hermeneutic approach on interpreting the Hinduism aesthetics text, as well as comparation with the science of architectural design. Its main literature refers to the Book of Natyashastra by Bharata Muni and its recontextualization process using dramaturgical analogies (Attoe, 1979) and the manifestations of the 'rasa' to the visual and architectural arts (Shetty and Bhoosan, 2017) and (Verma and Gupta, 2015). The results show that 'rasa' theory of Hindu aesthetics is relevant to developed into the contemporary architectural design. Relevance is not merely the conformity of the term alone, but also in conformity with the subject matter of architectural design such as science, form, spatial creation, architectural contexts as the present architectural design demands.

Keywords: 'hindu' aesthetics, interior design, recontextualization

Proses Review : 1 - 31 Maret 2018, Dinyatakan Lolos: 10 April 2018 


\section{PENDAHULUAN}

Perkembangan desain interior di Bali yang sangat masif ditopang oleh kemajuan industri Pariwisata di Bali. Yoshino (2010) memaparkan bahwa Bali telah memainkan peran sentral dalam mengembangkan wisata berbasis budaya. Slogan pariwisata Bali menegaskan sebagai "surga terakhir di dunia" melibatkan perkembangan visualisasi desain dengan mengangkat budaya sebagai komoditas pariwisata dan cara mempresentasikan elemen budaya ke dunia barat khususnya bagi wisatawan. Bali telah menjadi simbol wisata semacam ini. Ini bisa disebut sebagai "faktor Bali" (the Bali Factor), yang diidentikan dengan penggunaan dekorasi "orientalistik" yaitu dekorasi bergaya Bali dalam desain interior dan eksterior, serta keterampilan menyajikan produk jualan sebagai produk budaya kepada pelanggan asing.

Desain interior di Bali dalam mengedepankan the Bali Factor sebagai dasar pengembangannya menggunakan keunggulan arsitektur tradisional (vernakular), 'estetika Bali' dan ornamentasi dalam membangun ruang arsitektural dalam mengakomodasi kehidupan modern. Desain interior di Bali sebagai bagian dari arsitektur di Bali diatur dalam Perda Provinsi Bali No. 5 tahun 2005 tentang Persyaratan Arsitektur Bangunan Gedung, yang menyatakan dalam Pasal 1 ayat 12 yang berbunyi: "Gaya arsitektur tradisional Bali adalah corak penampilan arsitektur yang dapat memberikan citra/nuansa arsitektur berlandasarkan budaya Bali yang dijiwai oleh agama Hindu melalui penerapan berbagai prinsip bentuk yang mengandung identitas maupun nilai-nilai arsitektur tradisional Bali." Perda tersebut dengan tegas mengatur bahwa arsitektur tradisional Bali sebagai sumber inspirasi pengembangan desain interior kekinian di era pariwisata dijiwai oleh Agama Hindu. Implementasinya memerlukan usaha dari akademisi untuk merumuskan estetika Hindu dalam aplikasinya pada desain interior sebagai bagian dari kehidupan modern. Hal tersebut dilakukan sebagai upaya konservasi nilai budaya lokal dalam kehidupan global. Pemaparan awal menimbulkan pertanyaan penelitian yaitu bagaimana rekontekstualisasi estetika Hindu khususnya 'rasa' dalam desain arsitektural kekinian? Tulisan ini dijadikan studi awal (preliminary studies) untuk merumuskan bagian dari estetika Bali sebagai budaya lokal yang dapat dikembangkan ke tataran universal. Penulis menggunakan istilah desain arsitektural yang menyatakan keterkaitan antara arsitektur dan desain interior dalam pembahasannya.

\section{METODE}

Penelitian ini menggunakan kajian kepustakaan (library research) dengan pendekatan hermeneutik khususnya rekonstekstualisasi dalam menginterpretasikan objek penelitian berupa teks estetika Hindu, maupun komparasinya dengan keilmuan desain arsitektural secara interpretatif. Literatur utamanya mengacu ke Kitab Natyashastra oleh
Bharata Muni dan proses rekonstekstualisasinya menggunakan analogi dramaturgikal (Attoe, 1979) dan aplikasi 'rasa' ke seni visual dan arsitektur (Shetty dan Bhoosan, 2017) dan (Verma dan Gupta, 2015).

\section{PEMBAHASAN}

Raharja dkk (2012) menjelaskan bahwa rekontekstualisasi adalah proses masuk kembali ke dalam konteks publiknya. Penjelasan Sugiharto ini berkaitan dengan teori hermeneutik Paul Ricoeur, untuk menjelaskan kaitan hermeneutik dengan budaya lokal atau karya desain berbasis tradisi. Rekontekstualisai atau transfigurasi dalam hal ini merupakan proses suatu nilai budaya lokal atau nilai-nilai karya desain berbasis nilai tradisional disesuaikan dengan konteks zamannya. Dalam hal ini, konteks dan struktur yang kurang relevan bisa diabaikan, sebab yang ditekankan adalah hikmah atau relevansinya terhadap publik atau masyarakat saat ini. Dengan adanya rekontekstualisasi inilah peradaban bisa berlanjut. Piliang (2005: 5) menambahkan bahwa upaya pengembangan budaya lokal dalam konteks masa kini, di era globalisasi adalah dengan cara menempatkan (reposisi) budaya lokal tersebut di antara berbagai pilihan budaya yang ada, dalam rangka menemukan ruang dan peluang bagi keberlanjutan dan pengembangan budaya lokal itu sendiri. Untuk itu diperlukan reinterpretasi dan rekontekstualisasi, dalam rangka menemukan inovasi dan pengalaman estetik yang berbeda, tanpa merusak nilai-nilai dasar lokal. Pengembangan keunggulan lokal melalui inovasi tidak diartikan sebagai keterputusan atau diskontinuitas dari konteks lokal, akan tetapi dapat diartikan menghargai kembali nilai-nilai tradisi dan tidak mengkonservasinya secara kaku.

Desain arsitektural di Bali sebagai sebuah seni visual merupakan keberlanjutan dari perkembangan arsitektur Bali. Persilangan budaya dalam dialog budaya yang tercermin melalui visualisasinya merupakan warisan budaya material khususnya arsitektur yang wajib dikembangkan ke masa depan. Upaya pengembangan nilai arsitektur tradisional dan vernakular ke ranah modern oleh Cuthbert (2013: 18) dilakukan melalui pengembangan elemen:

Ideologi: Ekpresi dari teori atau prinsip panduan dalam arsitektur terbangun

Estetika: Apresiasi terhadap keindahan dan konversinya dalam pengunaan baru

Bentuk: Evolusi dari bentuk sederhana untuk mengakomodadi fungsi dan gaya baru

Fungsi: Adaptasi arsitektur vernakular ke atribut fungsional baru

Mimesis: Representasi atau imitasi dari 'dunia' nyata melalui seni (arsitektur) dengan mengambil beragam bentukan baru

Analogi: Kemiripan sebagain antara benda-benda

Metafora: Dimana sebuah bangunan ditetapkan sebagai representasi atau simbolik dari sesuatu yang lain

Totemisme: Representasi perlambang dari sebuah objek 
alam atau hewan yang memiliki signifikansi spiritual

Estetika sebagai bagian dari pengembangan tersebut memerlukan suatu konversi ke ranah modern. Estetika Bali belum dirumuskan secara definitif meskipun dalam tataran praktis telah diterapkan di segala aspek perikehidupan budaya material Bali. Dr. Anak Agung Madé Djelantik (1995) dalam Davies (2007) menyatakan bahwa tidak ada tulisan khusus mengenai estetika sebagai sebuah patokan resmi (discipline) di Bali'. Pembahasan mengenai seni sebagai bagian dari estetika di Bali tertulis dalam lontar kuno, tapi pada umumnya berhubungan dengan agama, spiritualitas, upacara dll. Jadi 'belum' ditemukan suatu rumusan estetika Bali yang dapat diaplikasikan ke ranah desain interior modern. Estetika Bali mungkin belum dirumuskan secara pasti, namun ketika berbicara pada tataran lebih luas, estetika Bali yang mayoritas dipengaruhi oleh Agama Hindu sangat erat dengan Estetika Hindu yang berkembang di India sebagai salah satu peletak fondasi budaya Bali.

\section{ESTETIKA HINDU}

Pengertian estetika dirumuskan oleh Suryajaya (2016: 1-3) sebagai 'filsafat kesenian'. Suryajaya memaparkan secara etimologis bahwa istilah 'estetika' berasal dari kata sifat dalam bahasa Yunani, 'aisthetikos', yang artinya 'berkenaan dengan persepsi'. Bentuk kata bendanya adalah 'aisthesis', yang artinya 'persepsi indrawi'. sementara bentuk kerja orang pertamanya adalah 'aishanomai', yakni 'saya mempersepsi'. Estetika mempunyai aspek kesejarahan yang panjang sebagai bagian dari filsafat. Penulis memfokuskan pada pembahasan estetika Hindu sebagai implementasi dari tujuan penulisan. Korelasi antara estetika Hindu dan estetika India sangat erat dan tidak dapat dipisahkan, dimana India sebagai sebuah Negara dikenal juga dengan nama 'Hindustan". Istilah tersebut secara literal berarti kawasan yang mengelilingi Sungai Indus (Elgood, 1999: 2). Sharma (2002) menyatakan penamaan 'Hindustan' berasal dari Bahasa Persia 'Hindu' dari pelafalan Bahasa Sansekerta 'Shindu'. Dalam konteks estetika, estetika India mempunyai beragam pembabakan disesuaikan dengan aspek kesejarahan dan perkembangan religiusitas sebagai inti dari filsafat estetikanya. Dalam konteks penulisan ini akan difokuskan pada estetika India dipengaruhi oleh Filsafat Hinduisme.

Penamaan Estetika Hindu di sini mengacu pada ideologi tentang Hindu atau hinduisme. Elgood (2000: 2) menegaskan bahwa Hinduisme harus dilihat dan dipahami tidak lebih dari sebuah sistem sosial, atau proses pabrikasi dari kebiasaan religius yang beragam, dibandingkan sebuah 'Agama'. Hinduisme akan selalu bersifat ekletik, melakukan praktik religius dan spiritual kuno dan menyerap yang lainnya sesuai ruang dan waktunya. Hal tersebut mengarahkan ke sebuah karakteristik toleransi beragama dan eklektikisme. Seni India secara umum menunjukkan intensitas religius dan sebuah tujuan yang bersifat metafisikal. Hal tersebut mengacu kepada skema pengetahuan tradisional, yang salah satunya tercantum dalam Kitab Natya Shastra yang membahas drama/tari klasik, yang mengungkapkan dan mengkomunikasikasikan perasaan dan emosi dari manusia. Hal tersebut dinamakan 'rasa' (Mukerjee, 1965).

\section{TEORI 'RASA'}

Suryajaya (2016: 244) memaparkan teori 'rasa' dalam estetika India yang mengakui aspek mimetik seni dan fungsi sosial seni seperti halnya estetika Klasik di Eropa. Beitmen (2014) menjelaskan bahwa Teori 'rasa' ditemukan dalam kitab kuno Natyashastra karangan Bharata Muni diperkirakan dibuat antara abad 2 SM dan 2 M. Natyashastra memaparkan teori dasar drama/teater klasik India dan rasa yang diantaranya menjelaskan bagaimana emosi manusia (penonton) bisa ditimbulkan melalui media drama (Verma dan Gupta, 2015). Teori rasa tertulis pada bagian rasasutra di Bab X Kitab Natyashastra yang berbunyi:

"vibhava anubhava vyabhicahribhava samyogat rasa nispatihi" yang berarti: 'Melaui kesatuan dari Vhibava (stimulus), Anubhava (reaksi spontan) dan Vyaribhava (reaksi sukarela) maka rasa akan muncul" (Damianova, 2014).

Kata rasa dibuat dari dua huruf ' $\mathrm{Ra}$ ' dan 'Sa', di mana Ra berarti "memberi” dan Sa berarti "gerak"(Verma dan Gupta, 2015). 'Rasa' berasal dari Bahasa Sansekerta 'rasah' yang mempunyai makna dan pemakaian yang bervariasi antara lain menurut Kamus Inggris-Sansekerta Monier-Williams (1979): Sap getah (sap), sari buah (juice), hakekat(isi/hakekat), sumsum (marrow), obat (potion), susu (milk), serum, air raksa (mercury), air mani (semen), dupa (myrrh), mineral, emas (gold), hijau (green), bawang (onion), getah damar (resin), rasa-indera pengecap (flavor), kemampuan merasakan(the faculty of taste), kesukaan (fondness), kesenangan (pleasure), perasaan yang dipengaruhi oleh estetika (aesthetics affect), perasaan (sentiment) dan watak/sikap batin (disposition) (Benamou, 2010). Dalam daftar itu, terbayang betapa kompleksnya konsep 'rasa' dalam estetika India. Bharata Muni membatasi pengertian 'rasa' dalam risalahnya sehingga hanya mencakup 'afeksi estetis', 'perasaan' dan 'sikap bathin'(Suryajaya, 2016: 248). Teori 'rasa' ini mempunyai dua aspek yaitu:

Rasavata yang berarti pengangkatan budi manusia ke dalam suasana dimana terjadi penikmatan keindahan sebagai kebahagiaan yang murni. Pengalaman ini adalah proses yang bersifat transedental.

Aspek presentasi atau penyajian yang terdiri dari tiga bagian yaitu:

Sthayi Bhava atau disebut juga sthayin adalah perwujudan 9 suasana jiwa yang kekal, yang tidak berubah

Vyabichari Bhava adalah suasana yang berlaku sementara bisa selalu berubah

Sattvika Bhava adalah tabiat atau watak (Vatsyayan dalam Djelantik, 1999).

Kitab Natyashastra sangat berpengaruh dalam sejarah es- 
tetika India dan dalam kitab tersebut dipaparkan sebuah konsep sentral yang banyak mempengaruhi estetika India hingga hari ini dan menyebar luas di Asia Tenggara, termasuk Indonesia (Suryajaya, 2016: 248). Kata 'rasa' telah disebutkan dalam berbagai konteks manuskrip mitologi Hindu seperti Rigveda, Satapatha Brahamna, Natyashastra, Vishnudharmottara Purana, dan Samrangana Sutradhara; yang merupakan manuskrip Hinduisme yang otentik (Damianova, 2014). Menurut Benamou (2010: 40) menyatakan bahwa 'rasa' dalam konteks musik dapat diterjemahkan menjadi 'sensasi' atau 'makna instrinsik (inner meaning). Namun kadangkala berarti 'kemampuan untuk mengekpresikan atau mencerap perasaan atau makna instrinsik'. Dalam kitab Natyashastra, apa yang dimaksud 'rasa' adalah pengalaman estetis pemirsa dalam mempersepsi sebuah karya seni, utamanya seni pertunjukan (drama atau teater klasik India).

Bharata Muni membagi 8 jenis 'rasa' antara lain:

Shrngara, adalah cinta, kegairahan atau ketertarikan. Dewanya Wisnu, warna: hijau Cerah pucat

Hasya adalah kelucuan, gembira dan komedi. Dewanya Pramata. Warna: Putih

Raudra adalah kemarahan. Dewanya Rudra. Warna: merah

Karuna adalah belas kasih, kasih sayang. Dewanya: Yama. Warna Abu-Abu

Bibhatsa adalah jijik/muak, keengganan. Dewanya Siwa. Warna biru

Bhayanaka adalah Horor, teror. Dewanya Kala. Warna hitam

Vira adalah perasaan kepahlawanan (heroik). Dewanya Indra, Warna kekuningan (yellowish).

Adbhuta adalah kekaguman, ketakjuban, Dewanya Brahma. Warnanya kuning (RTU, 2014).

Sampai abad ke-3 dan 4 masehi delapan 'rasa' (astarasa) ditambahkan menjadi sembilan rasa 'nawarasa' yaitu:

Shanta/Shantam atau Shanti adalah kedamaian atau ketenangan. Dewanya Wisnu. Warnanya putih (perpetual white). 'Rasa' kesembilan ditemukan pada Kitab Visnudharmottara dan Kitab Apparajitapracchha (Mukerjee, 1965). Shantam atau Shanti dipandang sebagai rasa tertinggi dalam nawarasa.

Dalam kitab Samrangana-sutradhara (ditemukan abad 11 Masehi) Sembilan rasa tersebut ditambahkan lagi 2 'rasa' menjadi 11 yang diekspresikan dalam citra dan lukisan; khusus dalam seni sastra menjadi:

Vatsalya adalah cinta orang tua (parental love)

Bhakti adalah cinta atau pelayanan total terhadap Tuhan dalam konteks spiritual

Rasa tidak selalu timbul dalam setiap kesenian. Hal itu baru timbul apabila sebuah karya mampu menghadirkan situasi emosi yang dapat ditangkap oleh penonton.

\section{KORELASI 'RASA' DAN EMOSI PENON- TON (BHAVA)}

Dick Hartoko dalam buku 'Manusia dan Seni' menjelaskan bahwa 'rasa' (Sansekerta) itu tidak sama dengan 'rasa' da- lam bahasa Indonesia. Kata 'rasa' dalam bahasa Indonesia kadangkala diartikan sebagai bagian dari 'perasaan' atau 'emosi', namun sebenarnya kedua kata tersebut (perasaan dan emosi) lebih dekat ke pengertian 'bhava' dalam bahasa Sansekerta (Ali, 2010: 72). Pernyataan yang sama juga diungkapkan oleh Suryajaya (2016: 250) yang menyatakan bahwa situasi emosi yang ditangkap oleh penonton yang akan menimbulkan 'rasa' tersebut disebut 'bhava'. Rasa tidak menghasilkan bhava, dan sebaliknya bhava tidak menghasilkan rasa. Sebaliknya, keduanya "menyebabkan satu sama lain untuk menjadi ada." Hal tersebut disebut dengan bhavayanti. Pengalaman estetika (aesthetics experience), seperti semua pengalaman, merupakan salah satu interaksi yang dinamis. Dick Hartoko (dalam Ali, 2010) menyebutkan bahwa sembilan 'rasa' (nawarasa) dalam Natya Shastra memang identik dengan sembilan 'bhava' (nawabhava) (lihat tabel 1), namun 'rasa' itu muncul dalam pengalaman estetik dan disaring melalui persepsi penonton, lihat gambar 1 .

Menurut Bharata Muni (dalam Mukerjee 1965), bhava dibagi menjadi Sthayi Bhava berarti 'kondisi dasar dari kesadaran' dan atau kondisi psikologis (Shetty dan Bhoosan, 2007) dan Vyabichari Bhava berarti 'perasaan sementara/transisi'; 'perasaan yang muncul (moods)'; dan Sattvika Bhava berarti 'tabiat atau watak' (Vatsyayan dalam Djelantik, 1999). Kesemua kondisi psikologis tersebut disebabkan oleh penyebab khusus/stimulus (vibhava) dan konsekuensinya/reaksi spontan (anubhava). Para peneliti sebelumnya telah memetakan hubungan antara rasa dan bhava, sehingga dapat dilihat korelasi antara warna dan perasaan/emosi yang ditimbulkan sebagai berikut:

Tabel 1. Hubungan Rasa dan Sthayi Bhava

\begin{tabular}{llll}
\hline Rasa & $\begin{array}{c}\text { [Sthayi] } \\
\text { Bhava }\end{array}$ & \multicolumn{1}{c}{ Makna } & Warna \\
\hline Shringara & Rati & Cinta/delight & $\begin{array}{l}\text { Pale Light } \\
\text { Green }\end{array}$ \\
\hline Hasya & Hasa & Kelucuan/Tawa & White \\
\hline Karuna & Shoka & $\begin{array}{l}\text { Kesedihan/Baik } \\
\text { hati }\end{array}$ & Grey \\
\hline Raudra & Krodha & Kemarahan & Red \\
\hline Veera & Utsaha & Kepahlawanan & Pale Orange \\
\hline Bhayanaka & Bhaya & Ketakutan/Bahaya & \\
\hline Bibhatsa & Jugupsa & $\begin{array}{l}\text { Kebencian/Keji- } \\
\text { jikan }\end{array}$ & Blue \\
\hline Adbhuta & Vismaya & $\begin{array}{l}\text { ketakjuban } \\
\text { Yellow }\end{array}$ \\
\hline
\end{tabular}




\begin{tabular}{lll}
\hline Shanta Shanta* & Kedamaian & $\begin{array}{l}\text { Perpetual } \\
\text { White }\end{array}$
\end{tabular}

Sumber: Kumar, 2015

Vyabichari Bhava adalah suasana perasaan yang berlaku sementara bisa selalu berubah, yang terdiri dari kesedihan (nirveda), kelemahan (glani), kecemasan (sanka), iri (asuya), mabuk (mada), kelelahan (srama), lamban (alasya), depresi (dainya), gelisah (cinta), gangguan (moha), ketenangan (smrti), kepuasan (dhrti), malu (vrida), sifat tidak tetap (capalata), kesenangan (harsa), hasutan (avega), pingsan (jadata), kesombongan (gar$v a$ ), putus asa (visada), ketidaksabaran (autsukya), tidur (nidra), epilepsi (apasmara), bermimpi (supta), bangun (vibodha), kemarahan (amarsa), disimilasi (avahitta), kekejaman (ugrata), jaminan (mati), penyakit (vyadhi), penyakit jiwa/gila (unmada), kematian (marana), ketakutan (trasa), pertimbangan (vitarka).

Sattvika Bhava adalah sesuatu yang ada dalam pikiran, watak dan atau tabiat. Hal ini disebabkan oleh pikiran terkonsentrasi dan proses pendalaman laku. 'Sattva' dicapai dengan konsentrasi pikiran. Sifatnya yang meliputi merinding (horripilation), air mata, tenang, tidak bisa ditiru oleh orang yang tidak berpikir. Sattva diinginkan dalam seni pertunjukan karena meniru sifat manusia. Sattvika Bhava terdiri dari keringat (sveda), kelumpuhan (stambha) dan gemetaran (prakampa), tangisan (asra), perubahan mimik wajah dan merinding (vaivarnya), perubahan suara (svara-pada) serta pingsan (pralaya). Kesemuanya itu adalah kondisi yang dikondisikan aktor dalam panggung. Dalam seni drama, akting, lukisan, patung, dan musik, 'sang aktor' atau seniman tidak terpengaruh pikirannya oleh sesuatu yang menggangu berasal dari orang lain dan situasi

tertentu. seniman memiliki konsentrasi yang melampaui orang, waktu, dan tempat, dan mengarahkan pikiran penonton menuju "keselarasan hati" (sahrdaya) dengan ketenangan (visranti). Presentasi artistik mengatasi kegelisahan pengamat yang disebabkan oleh gairah (rajas) dan ketidaktahuan atau kegelapan (tamas), dan mengenalkan keheningan dan kebahagiaan dari pikiran murni (sattvam). Pengalaman estetika menurut Bhatta-Nayaka, adalah pengalaman objek estetika universal oleh subjek universal dalam keadaan kebahagiaan sempurna (ananda), karena dominasi sattvam. Itulah sebabnya kenikmatan estetis dianggap serupa dengan kebahagiaan tertinggi ilahi (Brahmananda). (Vatsyayan dalam Djelantik, 1999).

Seluruh proses realisasi rasa dapat disimpulkan sebagai berikut: ketika seorang penonton yang ideal (sahrdya) yang berbakat spiritual dalam kedewasaan emosional dan sensitivitas estetika, menyaksikan sebuah permainan yang bagus di atas panggung, yang mempertunjukkan akting, musik, tari, dekorasi teater, kostum, dan sebagainya. Sang penonton menangkap tema permainan tersebut, tidak se- cara khusus/parsial tapi dalam konteks umum/holistik. Ketika tema drama terbebas dari batas waktu dan tempat, dan penonton menyingkirkan batasan ruang dan waktu serta dampaknya, maka ia menikmati kesenangan estetika (siddhi) (Shetty dan Bhoosan, 2007). Siddhi sebagai puncak tertinggi dari estetika pertunjukan drama India dapat dibagi menjadi manushi siddhi dan daiviki siddhi. Manushi siddhi berpusat pada reaksi penonton berdasarkan kesukaan atau ketidaksukaannya, sedangkan daiviki siddhi sebagai suatu pengalaman terhadap keluasan kesadaran yang ditandakan 'sesuatu' yang 'membanjiri' perasaan. Daiviki siddhi hanya dapat dicapai ketika penonton dalam keadaan mental yang tenang, diam dan menyerap penuh tanpa perasaan atau pikiran negatif (exaperation) (Mayaram, 2014).

\section{REKONTEKSTUALISASI 'RASA' DALAM DESAIN ARSITEKTURAL}

Teori 'rasa' seperti yang dipaparkan sebelumnya asalnya dari teori estetika Hindu khususnya tentang dramaturgi/ teater. Usaha merekontekstualisasi ke dalam wujud desain arsitektural memerlukan pemahaman analogi arsitektur dengan teater atau dramaturgikal. Wayne O. Attoe (1979: 31) dalam menjelaskan teori, kritik dan sejarah arsitektur menggunakan analogi dramaturgikal sebagai bagian dari penjelasannya. Aktivitas manusia dan lingkungan seringkali dianalogikan sebagai sebuah 'teater' atau 'panggung'. Pengguna ruang mempunyai perannya masing-masing dalam bangunan, sehingga penataan bangunan juga menjadi penataan panggung dan properti yang menunjang 'pertunjukan'nya. Istilah dramaturgikal dapat disusun yang berdekatan dengan keilmuan arsitektur yaitu penataan tempat dan adegan (setting), belakang panggung atau tempat operasional teater (backstage), peran yang berhubungan aktivitas dalam panggung (role), isyarat, kode atau tanda (cue), panggung depan (on stage), latar belakang (backdrop) dan garis pandang (sight lines).

Analogi dramaturgikal dalam arsitektur berfungsi dalam dua cara yaitu yaitu dari sudut pandang aktor dan dari sudut pandang pengarang drama (playwright). Langkah pertama seorang desainer arsitektural sebagai 'pencipta' ruang berkonsentrasi pada pemenuhan kebutuhan pengguna ruang dengan properti dan setting yang dibutuhkan dalam menjalankan 'aksi panggung'nya. Desainer arsitektural dari sudut pandang 'aktor' bertindak sebagai sutradara yang tidak kelihatan (invisible director) yang mengontrol dan memandu jalannya 'aksi panggung' para pengguna ruang (aktor) tersebut melalui media seluruh elemen arsitektural sebagai medium komunikasinya. 'Sutradara' harus mampu dan memahami posisi on stage yaitu pengguna dalam ruang inti arsitektural atau off stage pengguna dalam posisi dalam ruang penunjang arsitektural. Desainer sebagai 'sutradara' wajib mampu menggugah pengguna ruang sebagai 'aktor' agar menyatu dengan panggung dan juga mendapatkan 'rasa' kebersetubuhannya tersebut dalam bangunan sebagai 'panggung'. 


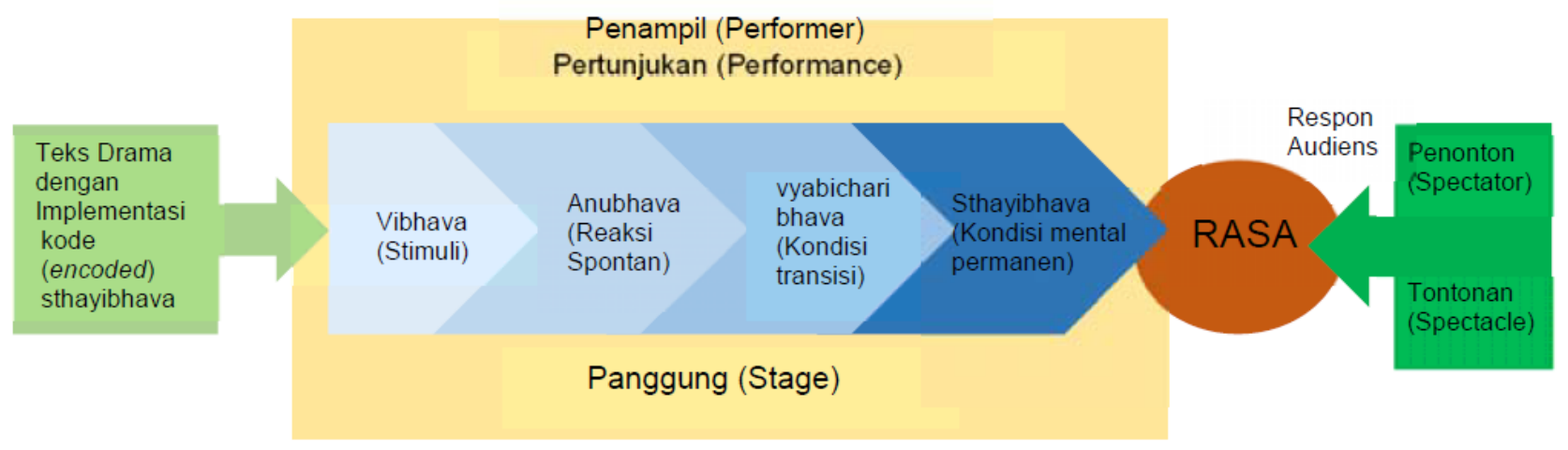

Gambar 1. Proses dari 'Bhava' menjadi 'Rasa' dalam Teater Sumber: Damianova (2014)

Desainer arsitektural dari sudut pandang pengarang cerita (playwright) harus mampu mengatur jalannya suatu pertunjukan melalui isyarat visual dalam ruang arsitektural. Tokoh utama diskenariokan melalui beragam adegan pertunjukan, untuk 'terus hidup' atau 'dibunuh' perannya dalam satu rangkaian pertunjukan untuk menggugah emosi penonton. Emosi penonton yang dalam teori 'rasa' dicampur adukan dengan beragam 'rasa' sehingga mencapai kondisi psikologis tetap yang permanen yaitu kesan terhadap pertunjukan tersebut secara mendalam dan susah dilupakan. Dalam hal tersebut, desainer arsitektural harus mampu menyusun sirkulasi atau pergerakan dalam ruang dengan mempertimbangan superordinat (dominasi) dan sub ordinat (submisif) dalam peran spasialnya. Ruangan sebagai panggung untuk 'peran' yang on stage ditata berdasarkan zonasi dimana terdapat ruang yang bersifat tertutup (introvert) atau terbuka (ekstrovert) yang mengundang ruang sentrifugal (menjauhkan) dan sentripetal (mendekatkan).

Terdapat sebuah diskursus antara aktor dan penonton dalam analogi dramaturgikal dalam arsitektur. Jika pengguna ruang adalah aktor siapakah penontonnya? pertanyaan tersebut muncul dikarenakan 'rasa' akan muncul dalam benak penonton (lihat gambar 1). Analogi dramaturgikal arsitektur dalam konteks teori rasa menghadirkan pengguna ruang sebagai 'aktor' sekaligus 'penonton' dalam panggung arsitektural. 'Rasa' menjadi sebuah perasaan kebertempatan (sense of places) pengguna ruang yang meningkatkan nilai keberikatan tempat (place attachments) pada sebuah bangunan arsitektural.

Kontekstualisasi 'rasa' dalam desain arsitektural merupakan kondisi psikologis pengguna ruang ketika berinteraksi dengan ruang. Kualitas ruang arsitektural dan pengaturan keseluruhan elemenya menentukan kualitas 'rasa' pengguna ruang tersebut. Desainer ketika mengetahui 'teori rasa' ini melakukan pendekatan yang spesifik dalam desain ruang dengan menganalogikan elemen dramaturgikal pada ruang arsitektural yang berkaitan (sequential).
Tabel 2. Rekontekstualisasi Bhava dalam Arsitektur

\begin{tabular}{ll}
\hline \multicolumn{1}{c}{ Jenis Bhava } & Rekontekstualisasi Arsitektur \\
\hline Vibhava (Stimulus) & $\begin{array}{l}\text { Konteks (sosial, ekonomi, } \\
\text { lingkungan, politik, sejarah) Ar- } \\
\text { sitektural, Elemen Arsitektural, } \\
\text { Arousal }\end{array}$ \\
\hline Anubhava (Reaksi Spon- & $\begin{array}{l}\text { Interaksi manusia dan Ruang, } \\
\text { Psikologis ruang }\end{array}$ \\
\hline Vyabichari Bhava (Kondi- & $\begin{array}{l}\text { Pemahaman ruang, Aktivitas, } \\
\text { Pengalaman dalam Ruang }\end{array}$ \\
\hline si Transisi) & $\begin{array}{l}\text { 'Rasa' Kebertempatan (Senses of } \\
\text { Place), 'Rasa” Keberikatan Tem- } \\
\text { pat (Place Attachment) }\end{array}$ \\
\hline Mental Permanen)
\end{tabular}

Konsep Sthayi Bhava (Sthayin) yang berhubungan dengan 9 'rasa' dalam arsitektur divisualisasikan dalam ruang dan waktu melalui beberapa cara. Manifestasi Visual tersebut digunakan dalam penggambaran sthayi bhava ke ranah desain arsitektural.

Shetty dan Bhoosan (2007) yang menyatakan bahwa dalam penciptaan bentuk ruang dalam arsitektur, seorang desainer arsitektural memiliki pemahaman inti bangunan di satu sisi (disebut juga

kavyartha); dan di sisi yang lain adalah kenikmatan artistik (siddhi) yang menghubungkan bentuk arsitektural dengan pengguna yang telah 'dewasa' pemikirannya. Shetty dan Bhoosan menerangkan aspek fungsional dari arsitektur (kavyartha) dan aspek citra (siddhi) dalam mempengaruhi psikologis pengguna ruang dalam arsitektural yang akan menimbulkan 'rasa'. 'Rasa' tersebut sebagai faktor yang menentukan arsitektur tersebut telah berfungsi maksimal. 

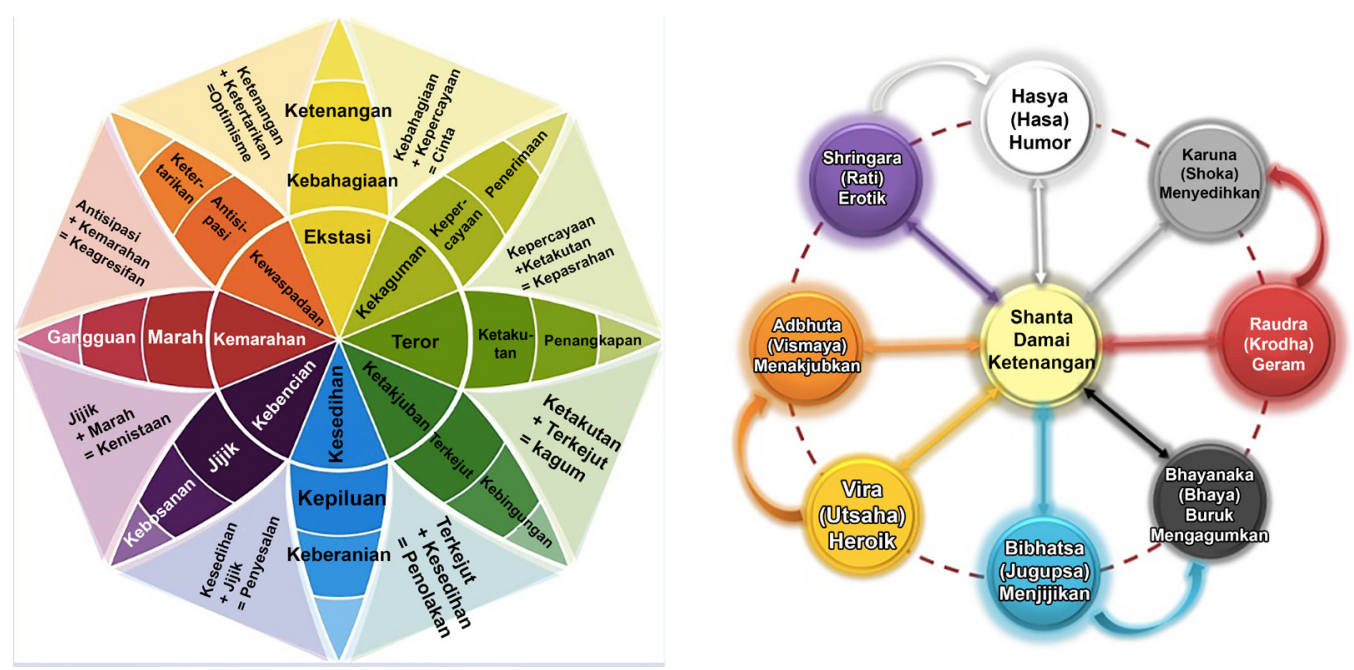

Gambar 2. Hubungan Warna dengan Rasa

Sumber: Kanan (Pollack, 2016) Kiri (Damianova, 2014)

Tabel 3. Visualisasi Sthayi Bhava dalam Bentuk Arsitektur

Bindu yaitu sebuah titik, yang membentuk tubuh yang menggambarkan dirinya sendiri

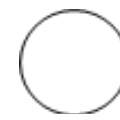

Manusia sebagai titik tolak perancangan, anthropometri
Nabhi yaitu 'jangkar' yang menunjukkan stabilitas dan pergerakan dalam keberaturan yang harmonis
Firmitas (Kekuatan), Utilitas (Fungsi) dan Venustas (Keindahan) yang salah satunya adalah keberaturan (order) sebagai prinsip desain arsitektural
Chakra yaitu roda yang melambangkan urutan siklus kehidupan dan kosmos

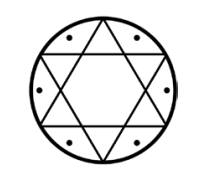

Aspek keberlanjutan (sustainability), Desain berwawasan ekologis (Eco Design), Arsitektur Organik
Mandala yaitu simbolisasi alam semesta (makrokosmos) dan badan manusia sebagai semesta kecil (mikrokosmos). Mandala adalah sebuah yantra (fokus meditasi) untuk mencapai kebahagiaan sempurna (ananda)

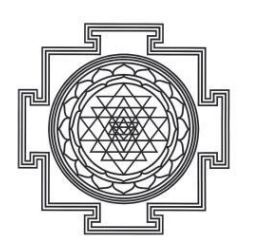

Arsitektur meningkatkan kualitas hidup manusia baik fisikal maupun spiritual (wellbeing space) dan menjadikan bumi menjadi lebih baik dan harmonis

Sumber: Rekontekstualisasi dari Shetty dan Bhoosan (2017) 
Dalam konteks penciptaan bentuk spasial arsitektur Shetty dan Bhoosan (2007) memaparkan vibhava dalam konteks arsitektur. Vibhava sebagai stimulus pemantik respon psikologis pengguna ruang dalam arsitektural merupakan penubuhan komunikasi 'sutradara' kepada 'penontonnya'. Vibhava bukanlah disebabkan semata-mata oleh material dalam bangunan dan bukan juga oleh sistem pertandaan dalam bangunan, namun sangat membantu dalam menciptakan suatu penataan elemen arsitektural yang kontekstual dan realistis. Hubungan spasial yang dipengaruhi oleh vibhava adalah ksetra (semua jenis ruang yang bersifat fisik, pembagian zona sampai ke penataan wilayah), loka (konsep ruang secara umum, paradigma arsitektural, tidak terikat secara fisik, materialitas, tanpa dimensi geografis atau historis), desa (sebuah konsep, tradisi , sejarah dan/ atau batas fisik yang mewakili satu ruang tunggal) dan kala yang mewakili periode waktu dalam bangunan. Anubhava adalah parameter organisasi untuk menciptakan variasi dalam konteks arsitektural. Situasi atau anubhava diciptakan dan dicontohkan dalam Sthayi bhava melalui pembagian temporal dan spasial (zonning/zonasi) (disebut Ksana), situasi/program ruang (disebut sandhi), koneksi/ hubungan (disebut sutra) dan hirarki ruang (disebut krama).

Vyabhicari bhava dalam konteks arsitektur adalah keadaan mental yang saling terjalin, yang saling melengkapi dengan sthayibhava. Keduanya mengambil bagian dari jutaan bentuk dan tingkat kemunculan yang beraneka ragam. Variasi dalam situasi atau konteks tertentu dalam ruang dan waktu dimodulasi, diakomodasi, didikte sesuai contoh variabel-variabel ini. Variabelnya adalah tala (pengguna ruang secara tetap (contohnya pegawai yang bekerja secara tetap dalam bangunan, atau terhubung dengan rutin seperti pada waktunya), laya (kecepatan atau kecepatan yang tercipta dalam ruang dan waktu, atau dapat diartikan sebagai durasi penggunaan dan jenis ruang), mana (variasi penekanan baik dalam ruang dan waktu, dalam ruang diartikan sebagai ruangan inti (core), dalam visualisasi diartikan penekanan (emphasys, point of interest) dalam konteks waktu dapat diartikan sebagai durasi tertinggi (rush hour) okupansi ruang). Hal ini berkaitan dengan irama, intensitas, jeda, istirahat, nada, fenomena pelanggaran dan regresi dalam ruang, dan hal lain yang menciptakan minat dan variasi sesuai urutan aktivitas dalam ruang (Shetty dan Bhoosan, 2007).

Dari pernyataan di atas dapat dlihat bahwa teori 'rasa' sebagai bagian dari estetika Hindu dapat diaplikasikan ke dalam desain arsitektural kekinian. 'Rasa' sebagai bagian dari pengalaman estetika dapat dikondisikan oleh situasi emosi yang disebut 'bhava'. Elemen arsitektural ditata sedemikian rupa untuk mencapai kedua hal tersebut terlepas dari ruang dan waktu. Pengalaman estetika 'rasa' mengantarkan 'pengamatnya' untuk mencapai kondisi psikologis transedental yang mengkonstruksi pengalaman kebertempatan dan meningkatkan kualitas okupansi ruang serta tempat.

\section{SIMPULAN}

Pemaparan di atas sebagai sebuah studi awal (preliminary studies) dapat dipahami bahwa estetika Hindu khususnya teori 'rasa' relevan dikembangkan ke dalam keilmuan desain arsitektural kekinian. Relevansi tersebut bukan semata penggantian atau kesesuaian istilah semata, namun juga kesesuaian dengan materi pokok arsitektur, bentuk, penciptaan spasial, konteks arsitektural sebagai tuntutan desain arsitektural kekinian. Hal tersebut menunjukkan kapabiltas teori rasa layak untuk dikembangkan sebagai patokan dalam pencarian desain berbasis budaya lokal berwawasan universal. Penelitian berikutnya layak untuk kembali merekontekstualisasi teori rasa ini dalam mempengaruhi psikologi pengguna ruang secara spesifik, korelasi dengan elemen ekspresi ruang dalam desain interior.

\section{DAFTAR RUJUKAN}

Agastia, IB, dalam Djelantik, A.A.M. (1999), Estetika Sebuah Pengantar, Bandung: Masyarakat Seni Pertunjukan Indonesia

Ali, M (2010), Konsep 'Rasa' dalam Estetika Nusantara, Prociding Seminar Nasional Estetika Nusantara, ISI Surakarta, 4 November 2010, Surakarta: ISI Press

Beitmen, LR. (2014), Neuroscience and Hindu Aesthetics: A Critical Analysis of V.S. Ramachandran's "Science of Art", Florida International University (FIU) Electronic Theses and Dissertations, 1198

Cuthbert, AR. (2013), Vernacular Transformations Context, Issues, Debates, artikel dalam Suartika, Gusti Ayu Made [eds.], 2013, Vernacular Transformation: Architecture, Place and Tradition, Denpasar: Pustaka Larasan dan Udayana University’s Master Program

Benamou, M (2010), Rasa: Affect in Javanese Musical Aesthetics, Oxford University Press

Daminova, R (2014), Sattvikabhinaya: The Modt Hidden Mode of Expression in Traditional Indian Theater and Dance Drama, Manas Studies into Asia and Africa Journal, South Asia: Identity and Cultural Diversity Issue 1/2014, Electronic Journal of the Centre for Eastern Languages and Cultures Sofia University "St. Kliment Ohridski”@ manas.bg

Djelantik, AAM (1995), "Is There a Shift Taking Place in Balinese Aesthetics?" Paper presented at the Third International Bali Studies Workshop, the University of Sydney, July 3-7, 1995, p. 2. 
Elgood, H (2000), Hinduism and The Religious Arts, London: Cassell

Maqbul, AS. (1986), "Hind: The Geography of India according to the Medieaeval Muslim Geographers", in B. Lewis; V. L. Ménage; Ch. Pellat; J. Schacht, The Encyclopedia of Islam, Volume III (H-IRAM)(Second ed.), Brill

Mayaram, S (2014), Philosophy as Samvada and Svaraj: Dialogical Meditations on Daya Krishna and Ramchandra Gandhi, Sage Publishing

Mukerjee, R. (1965), 'Rasas' as Springs of Art in Indian Aesthetics, The Journal of Aesthetics and Art Criticism, Vol. 24, No. 1, Oriental Aesthetics. (Autumn, 1965), pp. 91-96.

Peraturan Pemerintah Provinsi Bali Nomor 5 Tahun 2005 tentang Persyaratan Arsitektur Bangunan Gedung

Piliang, YA, (2005) "Menciptakan Keunggulan Lokal untuk Merebut Peluang Global: Sebuah Pendekatan Kultural". Denpasar: Makalah Seminar Seni dan Desain Institut Seni Indonesia Denpasar.

Pollack, D (2016), The Eight Rasas (Aesthetics Essences) Cheat Sheet, online artikel pdf on cheatography.com/2754/ cs/4817/

Raharja, IGM dan Artadi, IMP dan Maharani, IAD (2012) Rekonstekstualisasi Keunggulan Lokal Taman Peninggalan Kerajaan-Kerajaan di Bali Pada Era Globalisasi, Laporan Penelitian Fundamental, Denpasar: FSRD ISI Denpasar

Rai Technology University (RTU) (2014) Indian Aesthetics, Bangalore

Sharma, A (2002) On Hindu, Hindustan, Hinduism and Hindutva”, Numen, 49 (1): 1-36, JSTOR

Shetty, D dan Bhoosan, S (2007) Exploring Indian Aesthetic Theory for Developing New Architectural Forms, published in Proceedings of International Conference 'Sources of Architectural Forms: Theory and Practice' From March $10^{\text {th }}-13^{\text {th }} 2007$ by Department of Architecture, College of Petroleum and Engineering, Kuwait University, Kuwait.

Snyder, JC., dan Catanese, AJ (1979), Introduction of Architecture, New York: McGraw-Hill

Suryajaya, M (2016) Sejarah Estetika: Era Klasik Sampai Kontemporer, Jakarta: Penerbit Gang Kabel
Vatsyayan, KM (1999) Aesthetics Theories Underlying Asian Performing Arts dalam Djelantik, A.A.M., 1999, Estetika: Sebuah Pengantar, Bandung: Masyarakat Seni Pertunjukan Indonesia

Verma, A dan Gupta, I (2015) Indian Rasa in the Motifs of Saharanpur Woodcraft, American International Journal of Research in Humanities, Arts and Social Sciences, AIJRHASS 15-105, 2015

Yoshino, K (2010) Malaysian Cuisine: A Case of Neglected Culinary Globalization. In Globalization, Food and Social Identities in the Asia Pacific Region, ed. James Farrer. Tokyo: Sophia University Institute of Comparative Culture. 